Research article

\title{
Changes in $\gamma$-secretase activity and specificity caused by the introduction of consensus aspartyl protease active motif in Presenilin I
}

\author{
Donald B Carter ${ }^{1}$, Edwige Dunn ${ }^{1}$, Adele M Pauley², Denise D McKinley ${ }^{1}$, \\ Timothy J Fleck ${ }^{1}$, Brenda R Ellerbrook ${ }^{3}$, Nancy C Stratman ${ }^{3}$, \\ Xiangdong Zhou ${ }^{4}$, Carol S Himes ${ }^{1}$, Jeffrey S Nye ${ }^{1}$, Alfredo Tomasselli*2,5 and \\ Riqiang Yan*1,4
}

Address: ${ }^{1}$ Global Research and Development, Pfizer Inc. Kalamazoo, MI 49001, USA, ${ }^{2}$ Global Research and Development, Pfizer Inc. St Louis, MO 63017, USA, ${ }^{3}$ Global Research and Development, Pfizer Inc. Groton, CT 06340, USA, ${ }^{4}$ Department of Neurosciences, The Lerner Research Institute, Cleveland Clinic Foundation, Cleveland, OH 44195, USA and ${ }^{5}$ St Louis Laboratories Pfizer Inc., 700 Chesterfield Parkway West, Chesterfield, MO 63017, USA

Email: Donald B Carter - donald@ameritech.net; Edwige Dunn - EDunn@net-link.net; Adele M Pauley - adele.m.pauley@pfizer.com; Denise D McKinley - MCKINLEY_DENISE_D@LILLY.COM; Timothy J Fleck - timothy.j.fleck@pfizer.com; Brenda R Ellerbrook - brenda.r.ellerbrock@pfizer.com; Nancy C Stratman - nancy.c.stratman@pfizer.com; Xiangdong Zhou - zhoux@ccf.org; Carol S Himes - pooher@cs.com; Jeffrey S Nye - jnye@prdus.jnj.com; Alfredo Tomasselli* - alfredo.tomasselli@pfizer.com; Riqiang Yan* - yanr@ccf.org

* Corresponding authors

\section{Published: 12 May 2008}

Molecular Neurodegeneration 2008, 3:6 doi:10.1/86/1750-1326-3-6
Received: 16 January 2008

Accepted: 12 May 2008

This article is available from: http://www.molecularneurodegeneration.com/content/3/1/6

(C) 2008 Carter et al; licensee BioMed Central Ltd.

This is an Open Access article distributed under the terms of the Creative Commons Attribution License (http://creativecommons.org/licenses/by/2.0), which permits unrestricted use, distribution, and reproduction in any medium, provided the original work is properly cited.

\begin{abstract}
Presenilin (PSI or PS2) is an essential component of the active $\gamma$-secretase complex that liberates the $A \beta$ peptides from amyloid precursor protein (APP). PSI is regarded as an atypical aspartyl protease harboring two essential aspartic acids in the context of the sequence D257LV and D385FI, respectively, rather than the typical DTG...DTG catalytic motif of classical aspartyl proteases. In the present studies, we introduced the sequence DTG in PSI at and around the catalytic D257 and D385 residues to generate three PSI mutants: D257TG, D385TG, and the double-mutant D257TG/D385TG. The effects of these changes on the $\gamma$-secretase activity in the presence or absence of $\gamma$-secretase inhibitors and modulators were investigated. The results showed that PSI mutants having $D 385 T G$ robustly enhanced $A \beta_{42}$ production compared to the wild type (wt), and were more sensitive than wt to inhibition by a classical aspartyl protease transition state mimic, and fenchylamine, a sulfonamide derivative. Unlike wt PSI and some of its clinical mutants, all three PSI artificial mutants decreased cleavage of Notch S3-site, suggesting that these artificial mutations may trigger conformational changes at the substrate docking and catalytic site that cause alteration of substrate specificity and inhibition pattern. Consistent with this notion, we have found that NSAID enzymatic inhibitors of COX, known modulators of the $\gamma$-secretase activity, cause PSI mutants containing D385TG to produce higher levels of both $A \beta_{38}$ and $A \beta_{42}$, but to reduce levels of $A \beta_{39}$, showing a pattern of $A \beta$ formation different from that observed with wild type PSI and its clinical mutants. This study provides an important structural clue for the rational design of drugs to inhibit processing of APP at the $\gamma$-site without interfering with Notch processing.
\end{abstract}




\section{Introduction}

Strong evidence supports the notion that the aberrant formation and accumulation of $\beta$-amyloid peptides $(A \beta)$, generated from the $\beta$-amyloid-precursor protein (APP) by the action of $\beta$ - and $\gamma$-secretase, is a critical event in the pathology of familial and sporadic forms of Alzheimer's Disease (AD) [1-3]. APP is initially cleaved by $\beta$-secretase to generate membrane-bound C-terminal fragments (CTFs), and a soluble $\mathrm{N}$-terminal ectodomain $\mathrm{sAPP}_{\beta}$. Subsequently, those CTFs are cleaved by the $\gamma$-secretase within the putative transmembrane domain to release heterogeneous $\beta$-amyloid peptides (A $\beta$ ) composed of 37 to 43 amino acids; the 40 and 42 amino acids long peptides referred to as $A \beta_{40}$ and $A \beta_{42}$, respectively, are more predominant and the latter one is the most toxic to neurons [4]. Moreover, $\gamma$-secretase also cleaves APP at the $\varepsilon$-site (between L49 and V50), which resembles the $\gamma$-secretase S3 cleavage of Notch [5-8], and is located further downstream the $\gamma$-site with only 2-5 residues inside the cytoplasmic membrane [9]. Since the processing of Notch by the $\gamma$-secretase has important physiological implications, inhibition of its processing needs to be minimized in the development of $\gamma$-secretase inhibitors for AD therapy. Moreover, a variety of studies have already compiled a long list of potential $\gamma$-secretase cellular substrates that might further complicate selective inhibition of this enzyme. These substrates include CD44 [10], LRP [11], Erb4 [12], Nectin [13], E-cadherin [14]), and two membrane-bound ligands of Notch (Delta and Jagged) $[15,16]$.

Both biochemical and genetic approaches have led to the discovery that at least four membrane-bound proteins, presenilin (PS1 or PS2), nicastrin, aph1 and pen2, are needed to form an active $\gamma$-secretase complex $[17,18]$. Interestingly, only mutations in PS1 and PS2 but not in the other $\gamma$-secretase components are a common cause of the early onset familial Alzheimer's disease (FAD) [3]. PS1 and PS2 FAD mutants have been shown to increase the ratio of $A \beta_{42}$ over total $A \beta$ species [19-22] by affecting $\gamma$ secretase activity through still poorly understood mechanisms. Notwithstanding, recent studies have demonstrated that a significant increase in absolute levels of $A \beta_{42}$ was only observed for half of the mutations [23,24], further strengthening the notion that the mechanistic effects of PS1 mutations on the onset of FAD are complex.

Ample evidences suggest that PS1 (or PS2) is not only an indispensable component of a functional $\gamma$-secretase, but also is its catalytic core. In fact, complete deficiency of PS1 in mice abolishes the processing of both APP to release A $\beta$ and Notch at the S3 site to release NICD $[7,25]$. Strikingly, mutations of the aspartic acid residues to Ala or Glu in transmembrane segment 6 (TM6) (D257) and TM7 (D385) in PS1 or PS2 (numbering according to PS1) result in a dramatic reduction of $\gamma$-secretase activity [26], implying the possibility of these two aspartic residues constitute the active site of the $\gamma$-secretase. Aspartyl protease inhibitors, such as L-685,458 $[27,28]$ and difluoro ketones [29], were found not only to inhibit $\gamma$-secretase activity but also to locate or extract presenilins from cell homogenates by approaches including photoaffinity crosslink and affinity chromatography.

PS1 has a putative topology of nine-transmembrane domain (TM1 to TM9), and is matured and activated by cleavage between TM6 and TM7 by a highly regulated endoproteolytic cellular process that leaves behind tightly associated N- (NTF) and C-terminal fragments (CTF) [30]. Two conserved aspartic acids, D257 in TM6 and D385 in TM7, may potentially be positioned to face each other in an aqueous cavity within the lipid bilayer, and form the catalytic core [31]. Although mutation of either of these two conserved aspartic residues PS1 and PS2 impairs $\gamma$ secretase activity [32], they lack the two DTG (or DSG) triplets that form the catalytic pocket found in a typical aspartyl protease such as $\beta$-secretase [33] or HIV protease [34]. Similar to Presenilins, human signal peptide peptidase (SPP) possesses a pair of aspartic acids [35]. Moreover, SPP, PS1 and PS2 share highly conserved YD257 and GXGD385 (PS1 numbering) motifs and constitute a unique family of aspartyl protease [36].

While mutagenesis of residues surrounding the GXGD motif is reported $[31,37,38]$, the sequence and structural contexts following these two essential aspartyl proteases are not understood. In this study, we artificially introduced either one DTG triplet or both DTG triplets in PS1 and asked whether the DTG triplet could alter $\gamma$-secretase catalytic property due to a structural resemblance to a classical aspartyl protease. We found that neither the single D385TG nor the double triplet D257TG/D385TG were able to convert PS1 into a classic aspartyl protease. However, D385TG in particular, dramatically elevated $A \beta_{42}$ production, reinforcing the importance of residues surrounding D385 in the $\gamma$-secretase catalytic activity. More interestingly, PS1-D385TG significantly depressed the Notch S3-cleavage in releasing NICD, suggesting that the cleavage of APP at the $\gamma$-site and S3-site in Notch are differentially regulated. We also found that, unlike wt PS1 and other PS1 familial mutants, PS1-D385TG did not exhibit a biphasic profile on processing of APP in response to the inhibition by the $\gamma$-secretase inhibitors, L685,458 or fenchylamine. We, therefore, propose a possible model in which PS1-D385TG adopts a conformation, within the $\gamma$-secretase complex, that differs from that of wt-PS1 and favors the production of $A \beta_{42}$ but not NICD. This is the first demonstration that a mutation at F386I387 to TG causes such a dramatic effect in $\gamma$-secretase activity and inhibition. Because of its unique enzymatic profiles, PS1-D385TG will be valuable in a comparative 
structural exploration by approaches including electron microscope [39] as well as in rational design of drugs that specifically inhibit $A \beta$ production.

\section{Results \\ A DTG triplet in PSI enhances $A \beta_{42}$ production}

In order to explore the potential catalytic effect of the aspartic acid residues in PS1 TM 6 and 7 domains, we generated mutant PS1 including those containing either a single DTG triplet or both triplets after residue D257 or/and D385 (see Table 1). The transient transfection experiments were carried out with equal amount of each mutated PS1 construct and secreted $A \beta_{40}$ and $A \beta_{42}$ were measured by ELISA. Two stable cell lines, named H125.316 and H167-11 cell lines that express human APP carrying Swedish or London mutation respectively, were used for assessing changes of secreted $A \beta_{40}$ and $A \beta_{42}$. The values of $A \beta$ from the mock (empty pcDNA3 vector) transfected cells were used for normalization to calculate the \% change in $A \beta$ values obtained after transfection with the various plasmids shown in column 2. When the H125.316 cells were transfected with wild-type PS1 (wt-PS1), the ratio of $A \beta_{42}$ over total $A \beta$ was unchanged (Table 1). As expected, PS1 mutant carrying the familial mutation (PS1M146V) [40,41] cause a preferential production of $A \beta_{42}$ (Table 1). While mutant PS1 carrying a single DTG triplet at D257 (PS1-D257TG) behaved similar to wt PS1, mutant PS1 carrying a single DGT triplet at D385 (PS1D385TG) caused a remarkably increased production of $A \beta_{42}$ but not $A \beta_{40}$, and this increase was even more dramatic than the above mutants (Table 1). A mutant PS1 containing both the M146V and D385TG mutations was not any more productive in $A \beta_{42}$ secretion than either mutation separately (data not shown), suggesting no synergistic effect for these two mutations. Transient transfection of these PS1 mutant constructs into the human IMR32 neuroblastoma cells or a mouse neuroblastoma cell line N2A-APP, which expresses human Swedish APP as previously described $[42,43]$, also produced similar patterns of $A \beta$ levels (data not shown). We also generated sta- ble cells expressing both Swedish APP and various PS1 mutants as shown in Table 2. PS1 mutant harboring D385TG produced about 15-fold higher levels of $A \beta_{42}$ than control while $A \beta_{40}$ was only increased by 1.5 -fold than control (Table 2). Similarly, stable cells expressing PS1-D257TG/D385TG also produced significantly higher levels of $\mathrm{A} \beta_{42}$ than control cells.

A Western blot of protein extracts from transfected cells showed that transfected PS1 proteins in various cell lines are comparable (Figure 1), suggesting that the above shift of $A \beta_{42}$ in cells expressing mutant PS1 was not due to the dramatically altered expression of PS1 variants. Thus, generation of artificial DTG motif at D385 appears to dramatically favor the production of $A \beta_{42}$.

\section{The DTG triplet mimics PSI familial mutation}

Previously studies have shown that mutation of either D257 to A257 or D385 to A385 causes significant reduction of total $A \beta$ production [26]. To determine whether the enhanced $A \beta_{42}$ production seen in PS1-D385TG mutant was truly due to the introduction of an aspartyl protease DTG triplet, we then made substitutions to disrupt DTG motif in PS1-D385TG or PS1-D257TG/D385TG template. Interestingly, disruption of DTG motif in PS1D257Tㅅ/D385TG, PS1-D257TG/D385T스 or PS1-D385T쇼 template did not cause reversion of the $A \beta_{42} / A \beta_{\text {total }}$ ratio to the wt PS1 control (Table 3). Similar single mutation in BACE1 or HIV protease completely abolishes their proteolytic activity $[44,45]$. Thus, the presence of DTG triplet at D385 does not convert PS1 into a typical aspartyl protease, but rather creates a mutation that seems to resemble a PS1 mutation in FAD.

\section{PSI mutants display differential dose responses to $\gamma$ - secretase inhibitors}

The effects on the secretion of A $\beta$, caused by the PS1 mutants harboring the DTG triplet were explored by treating transfected cells with two well characterized $\gamma$-secretase inhibitors: L-685,458, an aspartyl protease transition

Table I: Transient transfection of various PSI constructs in HEK-293 cells derived stable cell lines expressing APP carrying Swedish mutation (HI25.3-16).

\begin{tabular}{ccccc}
\hline Cell Line & Transfected PSI Constructs & \% change A $\beta \mathbf{I - 4 0}$ & \% change A $\beta \mathbf{I - 4 2}$ & ratio of A $\beta 42 / \mathbf{A} \beta$ \\
\hline HI25.3-16 & PCDNA & - & - & $0.065 \pm 0.004$ \\
$"$ & PSI & -5.4 & -8.6 & $0.063 \pm 0.004$ \\
$"$ & PSI-MI46V & -10.5 & 33.7 & $0.095 \pm 0.004^{* *}$ \\
$" 1$ & PSI-D257TG & -5.4 & -3.6 & $0.060 \pm 0.003$ \\
$"$ & PSI-D385TG & -2.7 & 233.7 & $0.193 \pm 0.008^{*}$ \\
& PSI-D257TG/D385TG & -7.1 & 148.5 & $0.156 \pm 0.00 I^{*}$ \\
\hline
\end{tabular}

\footnotetext{
The levels of $A \beta 40$ and 42 were measured 48 hours post transfection.

** $\mathrm{p}<0.05$ as compared to PSI wt transfected cells $\mathrm{N}=3$

$* p<0.01$ as compared to PSI wt transfected cells

Note: Due to the variation of absolute $A \beta$ numbers in different experiments, only the comparative result to the cells transfected with pcDNA was used for comparison.
} 
Table 2: Examination of A $\beta$ values from conditioned media of HEK-293 derived stable cell lines expressing both Swedish APP and each of PSI genes.

\begin{tabular}{|c|c|c|c|c|}
\hline Cell Line & Transfected PSI Constructs & $A \beta I-40(p g / m l)$ & $A \beta I-42(p g / m l)$ & Ratio of $A \beta_{42} / A \beta$ \\
\hline HI25.3-16 & --- & $3152 \pm 47(n=6)$ & $337 \pm 36(n=6)$ & $0.097 \pm 0.010$ \\
\hline " & PSI & $8379 \pm 170(n=3)$ & $1123 \pm 20(n=6)$ & $0.118 \pm 0.002$ \\
\hline " & PSI-MI46V & $9507 \pm 129(n=3)$ & $2627 \pm 52(n=3)$ & $0.217 \pm 0.004^{* *}$ \\
\hline$"$ & PSI-D257TG & $9716 \pm 192(n=3)$ & $1099 \pm 35(n=6)$ & $0.102 \pm 0.003^{*}$ \\
\hline$"$ & PSI-D385TG & $7783 \pm 225(n=3)$ & $16647 \pm 799(n=3)$ & $0.681 \pm 0.033^{* *}$ \\
\hline " & PSI-D257TG/D385TG & $5390 \pm 218(n=3)$ & $6941 \pm 97(n=3)$ & $0.563 \pm 0.008^{* *}$ \\
\hline
\end{tabular}

$\mathrm{n}=3$ to 6 wells in one experiment. $A \beta$ represents total $A \beta$.

$*, \mathrm{p}<0.00 \mathrm{I}$, **, $\mathrm{p}<0.000 \mathrm{I}$ as compared to PSI wt transfected cells

state analog [46], and fenchylamine, a sulfonamide derivative [47]. Production of $A \beta_{40}$ was initially increased in APA2 cells (expressing both Swedish APP and wt PS1, $\triangle$ ), APD3 (expressing both Swedish APP and PS1-M146V, $\mathbf{\Delta}$ ) and their parental line H125.3-16 (expressing only Swedish APP, $\boldsymbol{\nabla}$ ) upon addition of L-685,458 up to $0.3 \mu \mathrm{M}$, but became reduced with the increased dose of L-685,458 while reaching a complete inhibition at $3 \mu \mathrm{M}$ (Figure 2A). The cell line APE12, expressing both Swedish APP and PS1-D257TG, showed a similar biphasic curve but in a lower dose range $(0.1 \mu \mathrm{M}$ and $1 \mu \mathrm{M}$, respectively; data not shown). Contrary to the above cases, cell lines expressing PS1 mutants PS1-D385TG (APB10,) and PS1-D257TG/ D385TG $($ APC5, +) did not display biphasic curves and showed inhibition of $A \beta_{40}$ production at all concentrations of the inhibitor used in the experiments. Interestingly, this non-biphasic curve was also seen in the cell line H167-11 expressing the London mutation APPV642F $(\square)$. This suggests that the conformational changes seen in APP London mutation are likely compatible with the D385TG mutation in PS1 during the interaction between the enzyme and its substrate; both facilitate $\gamma$-secretase to produce $A \beta_{42}$.

The biphasic effects of L-685,458 on $A \beta_{42}$ secretion from the cell lines expressing wt PS1 or familial PS1 mutation were even more robust than that on $\mathrm{A} \beta_{40}$ secretion (Figure 2B). Again, cell lines expressing either APP London mutation or D385TG triplet displayed no obvious biphasic effects. It appeared that L-685,458 has less inhibitory potency on $A \beta_{42}$ production than on $A \beta_{40}$ production as it required a higher dose to inhibit $A \beta_{42}$ than $A \beta_{40}$ in cells expressing PS1 carrying D385TG triplet. Cell toxicity was not obvious during the treatments with this drug up to 30 $\mu \mathrm{M}$ for any of the cell lines tested (data not shown),

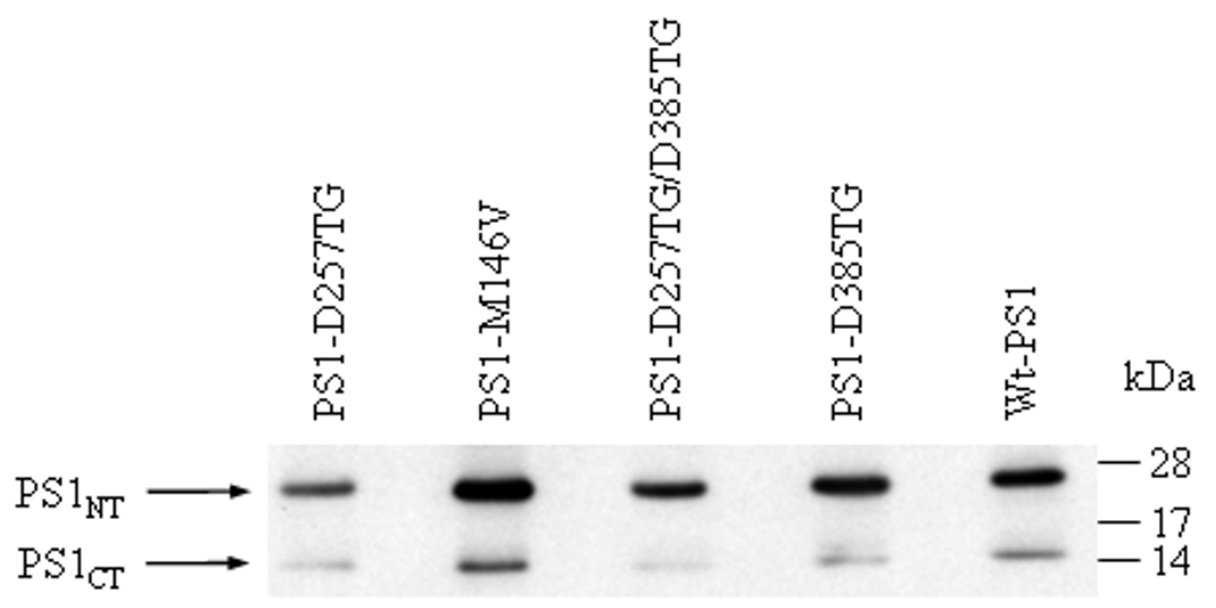

\section{Figure I}

Expression of PSI variants in each stable cell line. Western blot of equal amount of cell extracts from the stable cell lines expressing the indicated PSI variants. The blot was probed with mixed antisera recognizing both $\mathrm{N}$ - and $\mathrm{C}$-terminus of PSI. 
Table 3: Transient transfection of various PSI constructs in HEK-293 cells derived stable cell lines expressing APP carrying Swedish mutation (HI25-16).

\begin{tabular}{|c|c|c|}
\hline Cell Line & Transfected PSI Constructs & Ratio of $A \beta 42 / A \beta$ \\
\hline HI25.3-16 & PSI & $0.082 \pm 0.022$ \\
\hline " & PSI-D385TG & $0.261 \pm 0.029 * *$ \\
\hline$"$ & PSI-D385TA & $0.212 \pm 0.007^{* *}$ \\
\hline " & PSI-D257TA/D385TG & $0.186 \pm 0.010 * *$ \\
\hline$"$ & PSI- D257TG/D385TA & $0.171 \pm 0.005^{* *}$ \\
\hline
\end{tabular}

$A \beta 40$ and $A \beta 42$ levels were measured 48 hrs post-transfection. ** $\mathrm{p}<0.0$ I (versus PSI wt) $\mathrm{N}=3$

Changed residue in the DTG motif was shown in underlined.

excluding the possibility that the $\mathrm{A} \beta$ reduction seen in the above experiments was due to drug toxicity.

A biphasic production of $A \beta_{40}$ was also seen in H125.3-16 $(+), \mathrm{H} 143.3(\nabla)$, and APA2 $(\triangle)$ cell lines treated with the less potent $\gamma$-secretase inhibitor fenchylamine sulfonamide: it took $12 \mu \mathrm{M}$ to reach the peak of enzymatic activity and $30 \mu \mathrm{M}$ to achieve complete inhibition (Figure 3A). Cells expressing PS1-D257TG (APE12) were also more sensitive to the drug treatment with $3 \mu \mathrm{M}$ for the full stimulation (data not shown). Again, cells expressing PS1 D385TG mutants (APB10, O) showed highest sensitivity to the treatment with non-biphasic responses (Figure 3A). Similarly, there appeared no biphasic $\mathrm{A} \beta_{40}$ production in cells expressing APP London mutation when treated with fenchylamine sulfonamide.

For the production of $A \beta_{42}$, fenchylamine sulfonamide produced a large stimulus response on cells expressing endogenous PS1 or transfected wt PS1, but had a weak stimulating effect or no inhibition on the other cell lines (Figure 3B). The stimulating effect was probably due to the low potency of this drug on the inhibition of $\gamma$-secretase activity in producing $A \beta_{42}$, and the biphasic effect reflects a low inhibitory profile.

\section{NSAIDs display differential effects on PSI mutants}

The nonselective COX inhibitors NSAIDs Ibuprofen, Indomethacin and Sulindac sulfide (an active metabolite of the pro-drug Sulindac) have been shown to reduce $A \beta_{42}$ levels through increasing $A \beta_{38}$ production [48], suggesting that NSAIDs can modulate $\gamma$-secretase activity. We found that all of the above compounds lowered $A \beta_{42}$ secretion in a dose dependent manner in APB10 cell line expressing both Swedish APP and PS1-D385TG or APD cell line expressing both Swedish APP and the clinical mutation of PS1 M146V (Table 4). Sulindac sulfide was the most potent, followed by Indomethacin and Ibuprofen, showing $50 \%$ inhibition at about $30-50 \mu \mathrm{M}$ for Sulindac Sulfide, $50-150 \mu \mathrm{M}$ for Indomethacin and $300 \mu \mathrm{M}$ for Ibuprofen. The nonselective COX inhibitors NSAIDs Aspi-
A

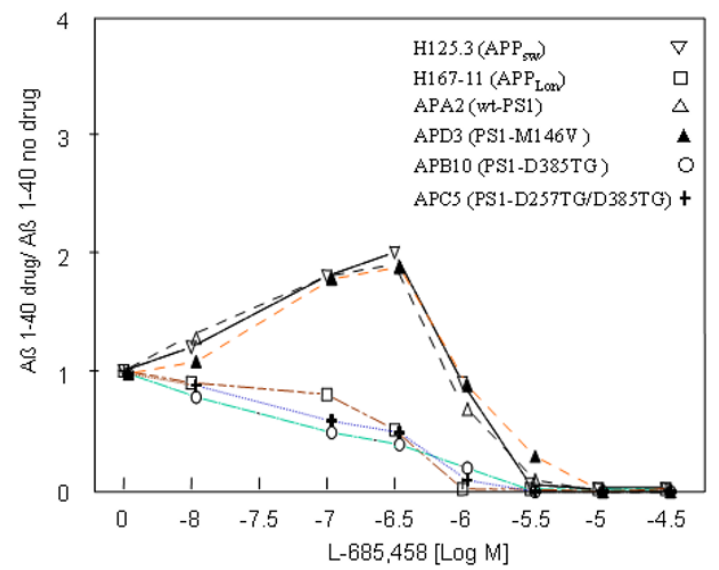

B

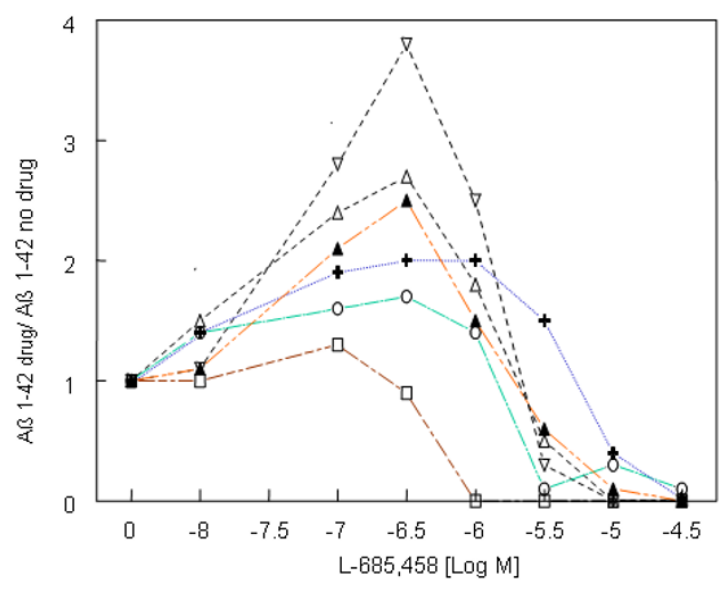

Figure 2

The relative $A \beta$ level secreted in the various stable cell lines treated with L-685,458. $A \beta_{40}(A)$ and $A \beta_{42}(B)$ were measured by ELISA 24 hours post treatment with the $\gamma$-secretase inhibitor L-685,458 $(n=2)$. The untreated samples were used for normalization. HI25.3-16 (APP-Sw, $\nabla$ ), APA2 (APP-Sw + PSI, $\triangle$ ), APBI0 (APP-Sw + PSI-D385TG, O), APC5 (APP-Sw + PSI-D257TG/D385TG, +), APD3 (APP-Sw + PSI-MI46V, A) and HI67-I I (APPV642F, $\square$ ).

rin (Acetylsalicylic acid) and Naproxen did not have any inhibitory effect (data not shown). The COX-2 NSAID inhibitor Meloxicam showed about 50\% inhibition at $300 \mu \mathrm{M}$ for both $A \beta_{40}$ and $A \beta_{42}$ which was similar to Ibuprofen for $A \beta_{42}$, while Ibuprofen showed no effect on $A \beta_{40}$ production.

To examine the $\mathrm{A} \beta$ species under the treated conditions, media from the three tested cell lines expressing PS1, PS1D385TG and PS1-M146V were collected, and A $\beta$ peptides were immunoprecipitated with monoclonal antibody 4G8. Sulindac Sulfide at a concentration of $100 \mu \mathrm{M}$ was chosen for treating the cell lines for its potent inhibitory effects seen in the above experiments. The immunoprecip- 
A

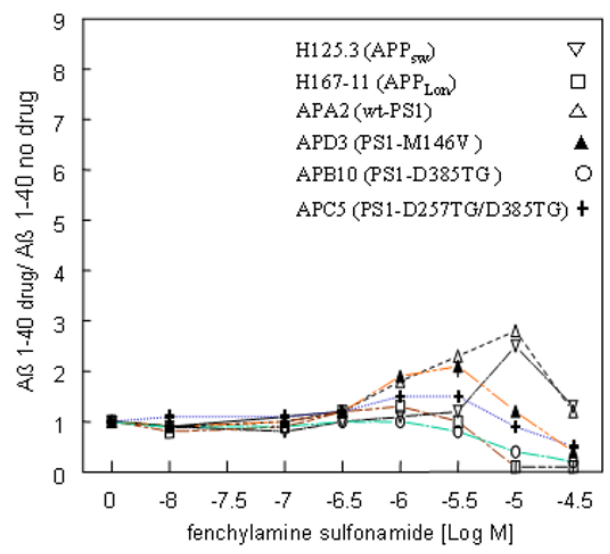

B

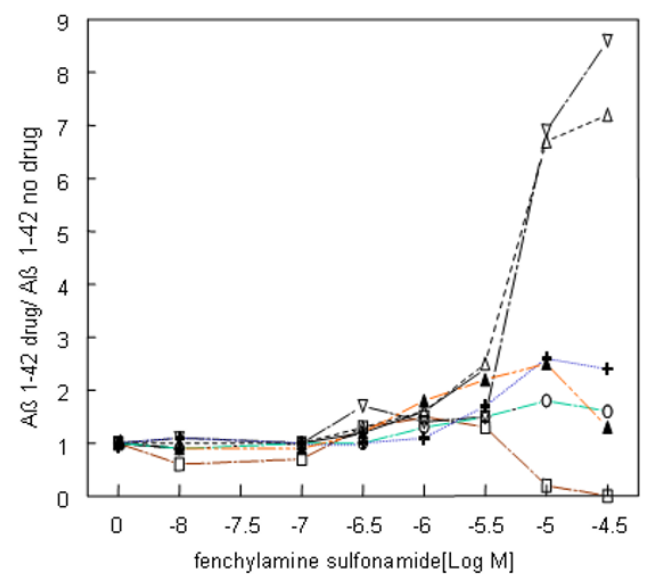

Figure 3

The relative $A \beta$ level secreted in the various stable cell lines treated with fenchylamine sulfonamide. $A \beta_{40}(A)$ and $A \beta_{42}(B)$ were measured by ELISA 24 hours post treatment with the $\gamma$-secretase inhibitor fenchylamine sulfonamide $(n=2)$. The untreated samples were used for normalization. The symbol for each cell lines is the same as in Figure 2.

itates were examined on bicine-urea gels to have better resolution of various $A \beta$ species [48]. As shown in Figure $4, \mathrm{~A} \beta_{40}$ was a predominant species in this wt-PS1 expressing H125.3-16 cell line (Figure 4, lane 1 ). $A \beta_{42}$ accounted for only $13 \%$ of total $A \beta$ species that is defined as the sum of the $A \beta 38,39,40$, and 42 bands (as determined by optical density measurements). As expected, the H125.3-16 cells treated with Sulindac Sulfide produced no measurable $A \beta_{42}$ while $A \beta_{38}$ was increased from $15 \%$ to $33 \%$ of total $A \beta$ species (Figure 4 lanes 2 ). Prior to any treatment, substantially more $A \beta_{42}$ was produced in PS1-D385TG expressing cells (Figure 4 lanes 3 ) than in cells expressing either endogenous levels of wt PS1 (lanes 1) or PS1M146V (lanes 5), and this was in consistent with the
ELISA results. The Western blot results also indicated that PS1-D385TG elevated $A \beta_{38}$ and $A \beta_{39}$ production, and the increased $A \beta_{42}$ species accounted for only $25 \%$ of the total $A \beta$ in PS1-D385TG-expressing cells instead of 33\% in PS1-M146V-expressing APC5 cells. After Sulindac Sulfide treatment, $A \beta_{42}$ formation was completely shifted to $A \beta_{38}$ in both H125.3-16 and APC5 cell lines (Figure 4, lanes 2 and 6$)$. However, $A \beta_{42}$ production was only partially reduced in PS1-D385TG-expressing cells under the same treatment conditions (Figure 4, lane 4). As noted, while the levels of $A \beta_{38}$ were increased from $25 \%$ of total $A \beta$ species to $33 \%$ in the PS1-D385TG expressing cells treated with $100 \mu \mathrm{M}$ Sulindac Sulfide, it was the $A \beta_{39}$ which had a more significant decline from $20 \%$ to undetectable in respect to the total $A \beta$ species (Figure 4, lane 4). Apparently, NSAID has differential affects on the selective cleavage of APP-CTFs by the $\gamma$-secretase activity when PS1 is mutated.

Differential effects on Notch S3-cleavage in PSI mutants Notch receptors undergo three distinct proteolytic cleavages during maturation and activation, and the third cleavage of Notch (S3 site) occurs within the plasma membrane by the PS1-containing $\gamma$-secretase and results in the release and translocation of the intracellular domain into the nucleus to execute Notch signaling [49]. To determine whether the PS1 mutations carrying the DTG triplet would affect Notch processing, we developed a protocol based on the translocation of the Notch intracellular domain (NICD) to the nucleus after S3 cleavage [50]. For each of the 5 cell lines examined, cleavage of Notch by the $\gamma$-secretase activity was determined based on luciferase activity that measures binding of NICD to the reporter. Figure 5 summarized results from three independent experiments. While the clinical mutation PS1M146V showed similar processing activity at the S3 site to the wild type PS1, a significant reduction of S3 cleavage was found in cells expressing PS1 mutants containing DTG motif at D385 (Figure 5). Specifically, the Notch cleavage activities of PS1-D385TG, PS1-DTG/DTG, PS1D257TG and PS1-M146V have decreased by about $62 \%$, $46 \%, 22 \%$ and $7 \%$, respectively, compared to PS1wt activity (Figure 5). Obviously, the mutations in PS1 containing a DTG motif caused a significant change in the conformation in the $\gamma$-secretase complex that is not favoring the cleavage of the Notch substrate.

\section{Discussion}

The triplets D257LV and D385FI, found in human PS1 TM 6 and 7, respectively, are conserved across species, and mutations of D257 and/or D385 to Ala result in essentially a complete loss of activity [26], suggesting that PS1 may function like an aspartyl protease. In addition, PS1 shares the YD257 and GxGD385 motifs with a unique family of aspartyl proteases referred to as signal peptidases 
Table 4: Effects of selected NSAID compounds on A $\beta$ production from indicated cell lines.

\begin{tabular}{|c|c|c|c|c|}
\hline Cell Lines & NSAID & Dose $(\mu \mathrm{M})$ & $\mathrm{A} \beta_{40}(\%$ of vehicle $)$ & $\mathrm{A} \beta_{42}(\%$ of vehicle $)$ \\
\hline \multirow[t]{12}{*}{ APC5 cell line } & (S) Ibuprofen & 0 & 100 & 100 \\
\hline & & 33 & $10 \mid \pm 8$ & $96 \pm 17$ \\
\hline & & 100 & $96 \pm 15$ & $79 \pm 21$ \\
\hline & & 300 & $70 \pm 13 *$ & $62 \pm 9 *$ \\
\hline & Indomethacin & 0 & 100 & 100 \\
\hline & & 33 & $101 \pm 11$ & $79 \pm 21$ \\
\hline & & 100 & $93 \pm 14$ & $53 \pm 12 *$ \\
\hline & & 300 & $68 \pm 11$ & $1 \mathrm{II} \pm 4 *$ \\
\hline & Sulindac Sulfide & 0 & 100 & 100 \\
\hline & & 11 & 103 & 88 \\
\hline & & 33 & $96 \pm 5$ & $64 \pm 2 *$ \\
\hline & & 100 & $57 \pm 2 *$ & $3 \pm 1 *$ \\
\hline \multirow[t]{12}{*}{ APD3 cell line } & (S) Ibuprofen & 0 & 100 & 100 \\
\hline & & 33 & $135 \pm 19$ & 88 \\
\hline & & 100 & $119 \pm 34$ & $64 \pm 2 *$ \\
\hline & & 300 & $103 \pm 36$ & $31 \pm 11 *$ \\
\hline & Indomethacin & 0 & 100 & 100 \\
\hline & & 33 & $95 \pm 22$ & $52 \pm 15 *$ \\
\hline & & 100 & $92 \pm 12 *$ & $13 \pm 11 *$ \\
\hline & & 300 & $72 \pm 16 *$ & $0 *$ \\
\hline & Sulindac Sulfide & 0 & 100 & 100 \\
\hline & & 11 & III & 76 \\
\hline & & 33 & $128 \pm 18$ & $56 \pm 4 *$ \\
\hline & & 100 & $64 \pm 10 *$ & $0 *$ \\
\hline
\end{tabular}

- * $p<0.05$

- Note: at II $\mu$ M Sulindac sulfide only one experiment was run which was the repeat experiment; due to the fact that this drug showed more potency than the others at lower doses that dose was added and the $300 \mu \mathrm{M}$ dose was omitted since it exhibited toxicity on the cells Each dose was run in triplicate.
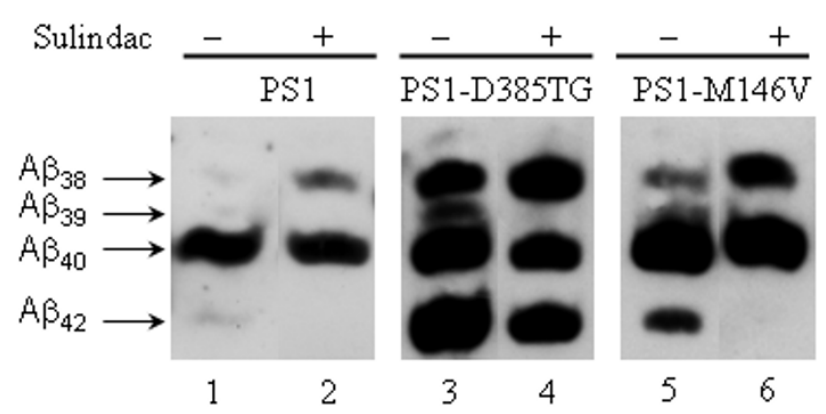

\section{Figure 4}

Western blot of immunoprecipitated $A \beta$ species. Conditioned media collected from the cell lines that express wt PSI, PSI-D385TG or PSI-MI46V and were treated with either DMSO or $100 \mu$ M Sulindac Sulfide. Equal amount of the media was immunoprecipitated with monoclonal antibody 4G8 and the extensively washed immunoprecipitates were resolved on a Tricine-Urea gel. The blot was reacted with antibody $6 \mathrm{E} I 0$ for detection.
(SPP) [35]. While the role of the amino acids comprising the YD257 and GxGD385 motifs have been studied, the couple of amino acids following D385, in particular F386, have not been tested. Since the two conserved catalytic aspartic acids D257 and D385 are not in the context of the two DTG (or DSG) catalytic triplets of a classical aspartyl protease [51], we artificially replaced L258V259 and/or F386I387 with TG in PS1 to generate two PS1 mutants D257TG and D385TG, and the double-mutant D257TG/ D385TG; we then investigated the effect of these mutations on $\gamma$-secretase catalytic activity in the presence or absence of $\gamma$-secretase inhibitors. Our data shows that expression of the PS1-D257TG in a stable cell line Swedish APP did not significantly alter the production of $A \beta_{40}$ or $A \beta_{42}$ (data not shown). However, when the same experiment was carried out with PS1-D385TG or PS1-D257TG/ D385TG, levels of $A \beta_{42}$ were increased at least 2.5 fold compared to that with wt PS1 whereas $A \beta_{40}$ remained largely unchanged. It appears that the mutation of F386I387 to T386G387 greatly favors the formation of $\mathrm{A} \beta_{42}$. 


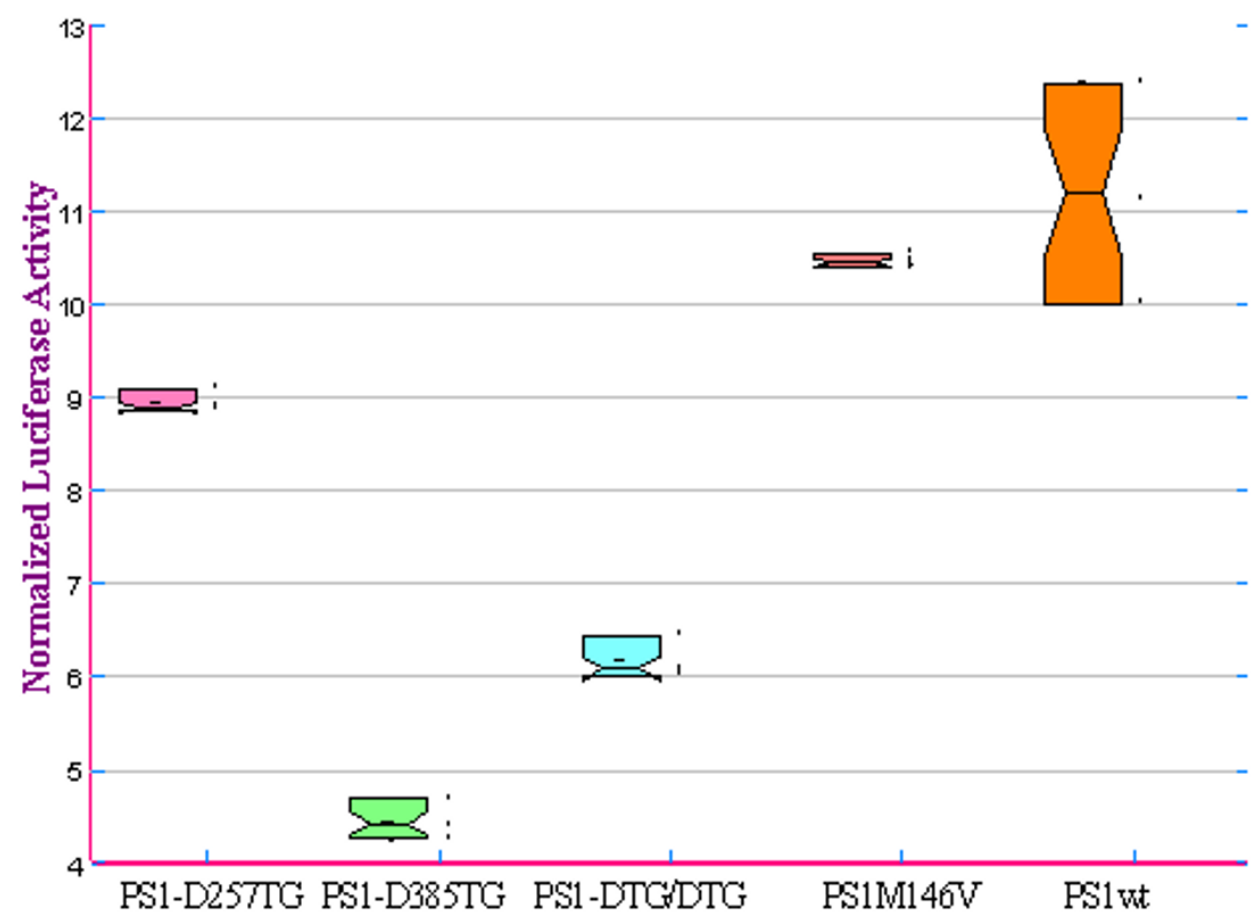

\section{Figure 5}

PSI carrying D385TG triplet suppresses NICD production. Each indicated stable cell was transfected with the Notch $\triangle E-G V P$, pFR-Luc and PRL-CMV. In Notch $\Delta E-G V P$, the Notch $\Delta E$ protein was fused to VPI6 transactivating protein domains (GVP). After the cleavage of the $N \Delta E G V P$ by the $\gamma$-secretase, the Notch $\Delta E$-GVP intracellular domain will translocate to the nucleus and binds to the GAL4 DNA binding domain located in the upstream of the reporter pFR-Luc to activates transcription. The results are the average of the three experiments.

Equally interestingly, the F386I387 to T386G387 mutation results in a significant reduction in processing of Notch at the S3 site APP $\varepsilon$-site (ITL49 $\downarrow$ V50ML) (Chen, 2001; Weidemann, 2002). Indeed, our preliminary experiments based on a reporter-depending assay suggested that both PS1-D385TG and PS1-D257TG/D385T also reduced processing at the APP $\varepsilon$-site (data not shown); yet, this latter observation needs to be fully validated. It appears that the mutation of F386I387 to T386G387 greatly favors the formation of $\mathrm{A} \beta_{42}$ and decreases the cleavage at both APP $\varepsilon$ - and Notch S3-site.

We have shown that this enhanced production of $A \beta_{42}$ in PS1-D385TG is not due to the conversion of PS1 into a classic aspartyl protease because the mutated triplet D385TA still increases production of $A \beta_{42}$ to a certain extent (Table 3). In light of these and other findings (Tolia et al, 2006; Yamasaki et al., 2006), it appears that mutating I387 may have a minor effect on the $\gamma$-secretase activity. Instead, the effect is driven by the F386 to T386 mutation. The presenilin and signal peptidase consensus motif GxGD has been studied with regard to its role in the context of the $\gamma$-secretase activity. Interestingly, the clinical
PS1 G384A mutant increased $A \beta_{42}$ production by a factor of 6 , but had no significant effect on Notch processing [52]. On the contrary, phenylalanine at position $\times$ of the GxGD385 motif in PS1 is suggested to be responsible for altering Notch processing [38]. Together with our findings that the mutation of F386 to T carries most of the responsibility for the observed change in substrate preference, we support the notion that the sequences surrounding the D385 may be critical in determining $\gamma$-secretase substrate recognition and docking, enzyme specificity and substrate cleavage rate. Although D257 is also implicated as a critical residue in cleaving APP at the $\gamma$-secretase site, PS1D257TG has less effect on the elevation of A $\beta 42$ and reducing Notch cleavage in our experiment. This weak effect is likely due to the presence of wild type PS1 in our cell lines as suggested by others [53].

Consistently, PS1-D257TG and PS1-D385TG mutants were also affected differently by $\gamma$-secretase inhibitors in our studies when compared to the wild type or clinical mutants. Both wild type and most PS1 variants showed biphasic curves, stimulation at low inhibitor concentration followed by inhibition at higher concentration, to the 
$\gamma$-secretase inhibitor L-685,458 while the PS1-D385TG mutants showed normal dose-dependent inhibitory curves within the test range. This stimulation/inhibition behavior has been reported for a variety of apparently unrelated inhibitors, including aspartyl protease transition state inhibitors, both in cells and in cell-free assay of $\gamma$-secretase activity [54-57]. Indeed, increases of $A \beta_{42}$ up to 8 -fold were observed at the peak elevation, and $A \beta 42$ constituted as much as $50 \%$ of the total secreted $\mathrm{A} \beta$ [54]. Among the various mechanisms suggested to justify this phenomenon there is one involving an allosteric modulation of the $\gamma$-secretase complex by a process similar to that responsible for the increase of $A \beta 42$ production by FAD mutations in presenilins, possibly related to structural changes; and another one related to inhibitor binding to either PS allosteric sites or the cell membrane which would cause structural changes in the preseniln structure to favor $A \beta 42$ production prior to reaching inhibitory concentrations. No matter which stimulation/inhibition mechanism is operative, our PS1-D385TG mutant distinguishes itself from wild type and other mutants in that this mutation has changed the enzyme structure sufficiently to have a significant effect in its ability to recognize and cleave substrates and be inhibited. On the other hand, the mutation leading to PS1-D257TG has much less influence on inhibition than PS1-D385TG; yet it may be able to induce some minor structural changes since it is inhibited by lower concentrations of inhibitor than the wild type enzyme (data not shown).

It has been reported that the $\gamma$-secretase is composed of one of each of the following proteins: presenilin, nicastrin, aph1 and pen2 [58]. If this stoichiometry is correct, our results would favor a model which comprises a $\gamma$ secretase catalytic site with D257 and D385 as catalytic residues and F386 involved in substrate docking with other residues possibly from the GLGD385 motif. However, a different stoichiometry involving two molecules of presenilin per $\gamma$-secretase complex has been reported (Clarke et al. 2006; Schroeter et al, 2003). If the latter stoichiometry is true, an additional model could also be possible where two C-terminal fragments or two N-terminal fragments form a homodimer with two D385s or two D257s, respectively, as catalytic residues. Based on the larger effect exhibited by mutations around D385 than those produced by mutations around D257, we suggest that the mutations F386I387 to T386G387, particularly F386 to T, following the catalytic residue D385 in TMD7 of PS, are involved in APP/Notch substrate selection and in substrate docking at the active site of $\gamma$-secretase.

Earlier work [48] showed that, in cultured cells, certain NSAIDs were able to decrease $A \beta_{42}$ secretion with concomitant increase in the $A \beta_{38}$, suggesting a correlation between $A \beta_{42}$ decrease/increase and $A \beta_{38}$ increase/ decrease. Recent work [59] has examined 10 clinical mutants of PS1 and shown that Sulindac Sulfide could increase the formation of $A \beta_{38}$ without affecting $A \beta_{42}$. Yet, these investigators observed that wt PS1 and even more PS1 M146L had a significant decrease of $A \beta_{42}$ and increase of $\mathrm{A} \beta_{38}$ upon treatment with $50 \mu \mathrm{M}$ sulindac sulfide. These latter observations are consistent, at least qualitatively, with those of the present study. Specifically, we show (Figure 4) that Sulindac Sulfide treated wt PS1, PS1 M146V, and PS1-D385TG, result in less $A \beta_{42}$ production with a significant $A \beta_{38}$ increase. Yet, while the two former proteins have a complete competence to produce $A \beta_{42}$, the latter one has totally lost its ability to form $A \beta_{39}$, and only partially that of making $A \beta_{42}$ and $A \beta_{40}$. The nature of these differences might be related to induction of conformational changes on these PS1 molecules by Sulindac Sulfide treatment [60] and are apparently different than those induced on most of the clinical mutants explored in the previous studies as reflected by the different effects on $\mathrm{A} \beta$ production [59].

In summary, we have, for the first time, demonstrated that a mutation at F386I387 to TG in PS1 causes a dramatic effect on $\gamma$-secretase activity with respect to higher productions of $A \beta_{42}$ compared to wt PS1, and differential proteolytic cleavages of its two studied substrates by increasing cleavage of APP after residue 42 (yielding $A \beta_{42}$ ) while decreasing the cleavage at the Notch S3-site. The knowledge gained from this study provides useful information in rational design and in the development of a protocol to screen compounds that only block the $\gamma$-secretase activity toward APP to release A $\beta$ but not the other substrates. PS1-D385TG can be used as a tool for comparative studies of structure and conformation in the $\gamma$-secretase complex.

\section{Materials and methods \\ Development of APPIPSI Stable Cell Lines}

HEK-293 cells were initially transfected with sixteen $\mu \mathrm{g}$ of DNA (pcDNA3.1/Hygro- vector inserted with either APP Swedish or London mutant. Two selected stable cell lines expressing Swedish APP were designated to be H143.3-23 and H125.3-16 while H167-11 for the cell line APP London mutant. A similar procedure was followed for the establishment of 125.3-16 cells that express PS1, PS1D385TG, PS1-D257TG/D385TG, PS1-M146V, or PS1D257TG cDNA inserts. The table below shows the nomenclature for the APP/PS1 stable cell lines and the clone used for follow-up studies. Three to ten clones were picked for each cell line and examined for the levels of $A \beta_{40}$ and $A \beta_{42}$ in conditioned media. The average ratio of $\mathrm{A} \beta_{42} /$ total-A $\beta$ for ten wt PS1-clones was $0.139 \pm 0.22$; $0.644 \pm 0.089$ for nine PS1-D385TG clones; $0.564 \pm 0.133$ for five PS1-D257TG/D385TG clones, $0.240 \pm 0.033$ for three PS1-M146V clones, and $0.087 \pm 0.044$ for ten PS1- 
D257TG clones. One clone for each PS1 DNA construct was selected from the set of clones for follow-up.

H125.3-16 APP-Sw

APA clone \#2 APP-Sw + PS1 wt

APB clone \#10 APP-Sw + PS1-D385TG

APC clone \#5 APP-Sw + PS1-D257TG/D385TG

APD clone \#3 APP-Sw + PS1-M146V

APE clone \#12 APP-Sw + PS1-D257TG

\section{Notch Assays}

Notch undergoes cleavage by the $\gamma$-secretase to release NICD that will translocate into nucleus to result in expression of target gene. To examine this cleavage, cell lines were seeded in 6 well dishes at $6 \times 10^{5}$ cells per $\mathrm{ml}(2 \mathrm{ml} /$ well) and each well was transfected with $6.25 \mathrm{ng}$ Notch $\triangle \mathrm{E}-\mathrm{GVP}[61], 1.55 \mu \mathrm{g}$ pFR-Luc (UAS-firefly luciferase, Stratagene), and $62.5 \mathrm{ng}$ pRL-CMV (renilla luciferase, Promega) for the luciferase assay or $2 \mu \mathrm{g}$ Notch $1 \Delta \mathrm{E}$ for the Notch the next day. After incubation for $3 \mathrm{hrs}$, transfection media was replaced with growth media and cells were allowed to grow for an additional 48 hrs. Luciferase assay were performed according to the protocols from manufacturer (Dual-Luciferase Reporter Assay System, Promega). Briefly, each well was washed twice with PBS and harvested with $500 \mu \mathrm{l}$ PLB buffer Lysates were transferred to eppendorf tubes and allowed to freeze at $-80^{\circ}$ for up to one week before being assayed. Lysates ( 2 or $20 \mu \mathrm{l}$ ) was transferred to each well of a 96 well plate and luciferase activity was measured using the Promega Dual-Luciferase reagents and a Lumiskan Ascent luminometer (ThermoLabsystems).

\section{ELISA Assay}

The analysis of $A \beta$ levels from conditioned media under specified conditions was performed as described previously [62]. Statistical analysis of the $A \beta_{40}$ and $A \beta_{42}$ levels was performed using the Student's t-test.

\section{Immunoprecipitation and Western blot Assay}

Cells were first grown in DMEM media for 24 hours in 6 well dishes to near confluence and then treated with drugs such as $100 \mu \mathrm{M}$ of sulindac sulfide in 1\% DMSO. After incubation for $24 \mathrm{hrs}$, one $\mathrm{ml}$ of conditioned media was used for immunoprecipitation with monoclonal antibody 4G8 under standard overnight immunoprecipitation conditions as described previously [63]. The extensively washed immunoprecipitates were resolved on a TricineUrea gel. For Western with cell lysates, cell extracts were prepared in TENT buffer (50 mM Tris pH 8.0, $150 \mathrm{mM}$
$\mathrm{NaCl}, 2 \mathrm{mM}$ EDTA and 1\% Triton X-100) with protease inhibitor cocktails. Equal amount of protein extracts were resolved on a $4-12 \%$ NuPage Bis Tris gel from Invitrogen (Carlsbad, CA). Monoclonal antibody 6E10 was used to detect $A \beta$ species.

\section{Drug Treatment}

Cells were plated at 50 to 100 thousand per well. After 48 hours, when cells were confluent, medium was replaced by cell medium containing the drug at each dilution. Each drug dilution was run in triplicate wells. After 24 hours incubation, half the volume of the conditioned cell medium was collected for measuring $A \beta_{40}$ and $A \beta_{42}$ by ELISA, while the remaining was saved for replication. The plate with the remaining cells was used for the MTS reduction assay to assess drug toxicity to the cells. All drugs were dissolved in DMSO at a concentration 1000 fold higher than the final drug concentration in the cell media for a final concentration of DMSO of $0.1 \%$. The drugs used were Fenchylamine, L-685,458 (from Bachem), Sulindac sulfide and sulfone (a second metabolite of Sulindac) (all from Biomol Research Labs Inc.), Acetylsalicylic acid (from ICN), (S)-Naproxen (from Cayman Chemical Co), Meloxicam (from Calbiochem). The experiment with the selective $\gamma$-secretase inhibitors was replicated. The comparison was made between $A \beta_{40}$ and $A \beta_{42}$ levels after drug treatment versus mock treated control. Cellular toxicity in treated cells was evaluated according to the procedures as previously described [64].

\section{Competing interests}

The authors declare that they have no competing interests.

\section{Acknowledgements}

RY is currently funded by NIH (AG025493), American Health Assistance Foundation and Alzheimer's Association.

\section{References}

I. Sisodia SS, Price DL: Amyloidogenesis in Alzheimer's disease: basic biology and animal models. Curr Opin Neurobiol 1992, 2:648-52.

2. Hardy J, Selkoe DJ: The amyloid hypothesis of Alzheimer's disease: progress and problems on the road to therapeutics. Science 2002, 297:353-6.

3. Tanzi RE, Bertram L: Twenty years of the Alzheimer's disease amyloid hypothesis: a genetic perspective. Cell 2005, 1 20:545-55.

4. Selkoe DJ, Wolfe MS: Presenilin: running with scissors in the membrane. Cell 2007, 131:215-21.

5. Struhl G, Greenwald I: Presenilin is required for activity and nuclear access of Notch in Drosophila. Nature 1999, 398:522-5.

6. Ray WJ, Yao M, Nowotny P, Mumm J, Zhang W, Wu JY, Kopan R, Goate AM: Evidence for a physical interaction between presenilin and Notch. Proc Natl Acad Sci USA 1999, 96:3263-8.

7. De Strooper B, Annaert W, Cupers P, Saftig P, Craessaerts K, Mumm JS, Schroeter EH, Schrijvers V, Wolfe MS, Ray WJ, Goate A, Kopan R: A presenilin-I-dependent gamma-secretase-like protease mediates release of Notch intracellular domain. Nature 1999, 398:518-22.

8. Okochi M, Steiner H, Fukumori A, Tanii H, Tomita T, Tanaka T, Iwatsubo T, Kudo T, Takeda M, Haass C: Presenilins mediate a dual 
intramembranous gamma-secretase cleavage of Notch-I. EMBO J 2002, $21: 5408-16$

9. Steiner H: Uncovering gamma-secretase. Curr Alzheimer Res 2004, I: |75-8I.

10. Lammich S, Okochi M, Takeda M, Kaether C, Capell A, Zimmer AK, Edbauer D, Walter J, Steiner H, Haass C: Presenilin-dependent intramembrane proteolysis of CD44 leads to the liberation of its intracellular domain and the secretion of an Abeta-like peptide. J Biol Chem 2002, 277:44754-9.

II. May P, Reddy YK, Herz J: Proteolytic processing of low density lipoprotein receptor-related protein mediates regulated release of its intracellular domain. J Biol Chem 2002, 277: $18736-43$

12. Lee HJ, Jung KM, Huang YZ, Bennett LB, Lee JS, Mei L, Kim TW: Presenilin-dependent gamma-secretase-like intramembrane cleavage of ErbB4. J Biol Chem 2002, 277:63 I8-23.

13. Kim DY, Ingano LA, Kovacs DM: Nectin-I alpha, an immunoglobulin-like receptor involved in the formation of synapses, is a substrate for presenilin/gamma-secretase-like cleavage. J Biol Chem 2002, 277:49976-8I.

14. Marambaud P, Shioi J, Serban G, Georgakopoulos A, Sarner S, Nagy V, Baki L, Wen P, Efthimiopoulos S, Shao Z, Wisniewski T, Robakis NK: A presenilin-I/gamma-secretase cleavage releases the E-cadherin intracellular domain and regulates disassembly of adherens junctions. EMBO / 2002, 21 : 1948-56.

15. LaVoie MJ, Selkoe DJ: The Notch ligands, Jagged and Delta, are sequentially processed by alpha-secretase and presenilin/ gamma-secretase and release signaling fragments. J Biol Chem 2003, 278:34427-37.

16. Ikeuchi T, Sisodia SS: The Notch ligands, Deltal and Jagged2, are substrates for presenilin-dependent "gamma-secretase" cleavage. J Biol Chem 2003, 278:775I-4.

17. Yu G, Nishimura M, Arawaka S, Levitan D, Zhang L, Tandon A, Song YO, Rogaeva E, Chen F, Kawarai T, Supala A, Levesque L, Yu H, Yan DS, Holmes E, Milman P, Liang Y, Zhang DM, Xu DH, Sato C, Rogaev E, Smith M, Janus C, Zhang Y, Aebersold R, Farrer LS, Sorbi S, Brun A, Fraser P, St George-Hyslop P: Nicastrin modulates presenilinmediated notch/glp-I signal transduction and betaAPP processing. Nature 2000, 407:48-54.

18. Francis R, McGrath G, Zhang J, Ruddy DA, Sym M, Apfeld J, Nicoll M, Maxwell M, Hai B, Ellis MC, Parks AL, Xu W, Li J, Gurney M, Myers RL, Himes CS, Hiebsch R, Ruble C, Nye JS, Curtis D: aph-I and pen$\mathbf{2}$ are required for Notch pathway signaling, gamma-secretase cleavage of betaAPP, and presenilin protein accumulation. Dev Cell 2002, 3:85-97.

19. Duff K, Eckman C, Zehr C, Yu X, Prada CM, Perez-tur J, Hutton M, Buee L, Harigaya Y, Yager D, Morgan D, Gordon MN, Holcomb L, Refolo L, Zenk B, Hardy J, Younkin S: Increased amyloidbeta42 [43] in brains of mice expressing mutant presenilin I. Nature 1996, 383:710-3.

20. Borchelt DR, Thinakaran G, Eckman CB, Lee MK, Davenport F, Ratovitsky T, Prada CM, Kim G, Seekins S, Yager D, Slunt HH, Wang R, Seeger M, Levey Al, Gandy SE, Copeland NG, Jenkins NA, Price DL, Younkin SG, Sisodia SS: Familial Alzheimer's disease-linked presenilin I variants elevate Abeta I-42/I-40 ratio in vitro and in vivo. Neuron 1996, 17:1005-13.

21. Tomita T, Maruyama K, Saido TC, Kume H, Shinozaki K, Tokuhiro S, Capell A, Walter J, Grünberg J, Haass C, Iwatsubo T, Obata K: The presenilin 2 mutation (NI4II) linked to familial Alzheimer disease (Volga German families) increases the secretion of amyloid beta protein ending at the $42 \mathrm{nd}$ (or $43 \mathrm{rd}$ ) residue. Proc Natl Acad Sci USA 1997, 94:2025-30.

22. Lemere CA, Lopera F, Kosik KS, Lendon CL, Ossa J, Saido TC, Yamaguchi H, Ruiz A, Martinez A, Madrigal L, Hincapie L, Arango IC, Anthony DC, Koo EH, Goate AM, Selkoe DJ, Arango JC: The E280A presenilin I Alzheimer mutation produces increased A beta 42 deposition and severe cerebellar pathology. Nat Med 1996 , 2:1146-50.

23. Kumar-Singh S, Theuns J, Van Broeck B, Pirici D, Vennekens K, Corsmit E, Cruts M, Dermaut B, Wang R, Van Broeckhoven C: Mean age-of-onset of familial alzheimer disease caused by presenilin mutations correlates with both increased Abeta42 and decreased Abeta40. Hum Mutat 2006, 27:686-95.

24. Shioi J, Georgakopoulos A, Mehta P, Kouchi Z, Litterst CM, Baki L, Robakis NK: FAD mutants unable to increase neurotoxic Abeta 42 suggest that mutation effects on neurodegenera- tion may be independent of effects on Abeta. I Neurochem 2007, 10 I:674-8I.

25. De Strooper B, Saftig P, Craessaerts K, Vanderstichele H, Guhde G, Annaert W, Von Figura K, Van Leuven F: Deficiency of presenilinI inhibits the normal cleavage of amyloid precursor protein. Nature 1998, 391:387-90.

26. Wolfe MS, De Los AJ, Miller DD, Xia W, Selkoe DJ: Are presenilins intramembrane-cleaving proteases? Implications for the molecular mechanism of Alzheimer's disease. Biochemistry 1999, 38: I I223-30

27. Li YM, Lai MT, Xu M, Huang Q, DiMuzio-Mower J, Sardana MK, Shi $X P$, Yin KC, Shafer JA, Gardell SJ: Presenilin I is linked with gamma-secretase activity in the detergent solubilized state. Proc Natl Acad Sci USA 2000, 97:6I38-43.

28. Li YM, Xu M, Lai MT, Huang Q, Castro JL, DiMuzio-Mower J, Harrison T, Lellis C, Nadin A, Neduvelil JG, Register RB, Sardana MK, Shearman MS, Smith AL, Shi XP, Yin KC, Shafer JA, Gardell SJ: Photoactivated gamma-secretase inhibitors directed to the active site covalently label presenilin I. Nature 2000, 405:689-94.

29. Esler WP, Kimberly WT, Ostaszewski BL, Diehl TS, Moore CL, Tsai JY, Rahmati T, Xia W, Selkoe DJ, Wolfe MS: Transition-state analogue inhibitors of gamma-secretase bind directly to presenilin-I. Nat Cell Biol 2000, 2:428-34

30. Thinakaran G, Borchelt DR, Lee MK, Slunt HH, Spitzer L, Kim G, Ratovitsky T, Davenport F, Nordstedt C, Seeger M, Hardy J, Levey AI, Gandy SE, Jenkins NA, Copeland NG, Price DL, Sisodia SS: Endoproteolysis of presenilin I and accumulation of processed derivatives in vivo. Neuron 1996, 17:181-90.

31. Tolia A, Chavez-Gutierrez L, De SB: Contribution of presenilin transmembrane domains 6 and 7 to a water-containing cavity in the gamma-secretase complex. J Biol Chem 2006, 28I:27633-42.

32. Wolfe MS: The gamma-secretase complex: membraneembedded proteolytic ensemble. Biochemistry 2006, 45:793I-9.

33. Yan R, Bienkowski MJ, Shuck ME, Miao H, Tory MC, Pauley AM, Brashier JR, Stratman NC, Mathews WR, Buhl AE, Carter DB, Tomasselli AG, Parodi LA, Heinrikson RL, Gurney ME: Membraneanchored aspartyl protease with Alzheimer's disease betasecretase activity. Nature 1999, 402:533-7.

34. Dunn BM: Structure and mechanism of the pepsin-like family of aspartic peptidases. Chem Rev 2002, 102:443I-58.

35. Weihofen A, Binns K, Lemberg MK, Ashman K, Martoglio B: Identification of signal peptide peptidase, a presenilin-type aspartic protease. Science 2002, 296:2215-8.

36. Haass C, Steiner H: Alzheimer disease gamma-secretase: a complex story of GxGD-type presenilin proteases. Trends Cell Biol 2002, 12:556-62.

37. Kornilova AY, Bihel F, Das C, Wolfe MS: The initial substratebinding site of gamma-secretase is located on presenilin near the active site. Proc Natl Acad Sci USA 2005, 102:3230-5.

38. Yamasaki A, Eimer S, Okochi M, Smialowska A, Kaether C, Baumeister R, Haass $C$, Steiner $\mathrm{H}$ : The GxGD motif of presenilin contributes to catalytic function and substrate identification of gamma-secretase. J Neurosci 2006, 26:382I-8.

39. Lazarov VK, Fraering PC, Ye W, Wolfe MS, Selkoe DJ, Li H: Electron microscopic structure of purified, active gamma-secretase reveals an aqueous intramembrane chamber and two pores. Proc Natl Acad Sci USA 2006, 103:6889-94.

40. Campion D, Flaman JM, Brice A, Hannequin D, Dubois B, Martin C, Moreau V, Charbonnier F, Didierjean O, Tardieu S, et al.: Mutations of the presenilin I gene in families with early-onset Alzheimer's disease. Hum Mol Genet 1995, 4:2373-7.

4I. Rogaeva EA, Fafel KC, Song YQ, Medeiros H, Sato C, Liang Y, Richard E, Rogaev El, Frommelt P, Sadovnick AD, Meschino W, Rockwood K, Boss MA, Mayeux R, St George-Hyslop P: Screening for PSI mutations in a referral-based series of $A D$ cases: 21 novel mutations. Neurology 200I, 57:62I-5.

42. Qahwash I, He W, Tomasselli A, Kletzien RF, Yan R: Processing amyloid precursor protein at the beta-site requires proper orientation to be accessed by BACEI. J Biol Chem 2004, 279:39010-6

43. Tomasselli AG, Qahwash I, Emmons TL, Lu Y, Leone JW, Lull JM, Fok KF, Bannow CA, Smith CW, Bienkowski MJ, Heinrikson RL, Yan R: Employing a superior BACEI cleavage sequence to probe cellular APP processing. J Neurochem 2003, 84:1006-17. 
44. He W, Lu Y, Qahwash I, Hu XY, Chang A, Yan R: Reticulon family members modulate BACEI activity and amyloid-beta peptide generation. Nat Med 2004, 10:959-65.

45. Loeb DD, Swanstrom R, Everitt L, Manchester M, Stamper SE, Hutchison CA III: Complete mutagenesis of the HIV-I protease. Nature 1989, 340:397-400.

46. Shearman MS, Beher D, Clarke EE, Lewis HD, Harrison T, Hunt $P$, Nadin A, Smith AL, Stevenson G, Castro JL: L-685,458, an aspartyl protease transition state mimic, is a potent inhibitor of amyloid beta-protein precursor gamma-secretase activity. Biochemistry 2000, 39:8698-704.

47. Rishton GM, Retz DM, Tempest PA, Novotny J, Kahn S, Treanor J], Lile JD, Citron M: Fenchylamine sulfonamide inhibitors of amyloid beta peptide production by the gamma-secretase proteolytic pathway: potential small-molecule therapeutic agents for the treatment of Alzheimer's disease. J Med Chem 2000, 43:2297-9.

48. Weggen S, Eriksen JL, Das P, Sagi SA, Wang R, Pietrzik CU, Findlay KA, Smith TE, Murphy MP, Bulter T, Kang DE, Marquez-Sterling N, Golde TE, Koo EH: A subset of NSAIDs lower amyloidogenic Abeta42 independently of cyclooxygenase activity. Nature 200I, 4I 4:2I 2-6.

49. Kopan R, Turner DL: The Notch pathway: democracy and aristocracy in the selection of cell fate. Curr Opin Neurobiol 1996, 6:594-60l.

50. Schroeter EH, Kisslinger JA, Kopan R: Notch-I signalling requires ligand-induced proteolytic release of intracellular domain. Nature 1998, 393:382-6.

5I. John V, Beck JP, Bienkowski MJ, Sinha S, Heinrikson RL: Human beta-secretase (BACE) and BACE inhibitors. I Med Chem 2003, 46:4625-30.

52. Steiner H, Kostka M, Romig H, Basset G, Pesold B, Hardy J, Capell A, Meyn L, Grim ML, Baumeister R, Fechteler K, Haass C: Glycine 384 is required for presenilin-I function and is conserved in bacterial polytopic aspartyl proteases. Nat Cell Biol 2000, 2:848-5I.

53. Xia $X$, Wang $P$, Sun $X$, Soriano $S$, Shum WK, Yamaguchi $H$, Trumbauer ME, Takashima A, Koo EH, Zheng $\mathrm{H}$ : The aspartate-257 of presenilin $\mathrm{I}$ is indispensable for mouse development and production of beta-amyloid peptides through beta-cateninindependent mechanisms. Proc Natl Acad Sci USA 2002, 99:8760-5.

54. Durkin JT, Murthy S, Husten EJ, Trusko SP, Savage MJ, Rotella DP, Greenberg BD, Siman R: Rank-order of potencies for inhibition of the secretion of abeta 40 and abeta 42 suggests that both are generated by a single gamma-secretase. J Biol Chem 1999 274:20499-504

55. Wolfe MS, Xia W, Moore CL, Leatherwood DD, Ostaszewski B, Rahmati T, Donkor IO, Selkoe DJ: Peptidomimetic probes and molecular modeling suggest that Alzheimer's gamma-secretase is an intramembrane-cleaving aspartyl protease. Biochemistry 1999, 38:4720-7.

56. Murphy MP, Uljon SN, Fraser PE, Fauq A, Lookingbill HA, Findlay KA, Smith TE, Lewis PA, McLendon DC, Wang R, Golde TE: Presenilin I regulates pharmacologically distinct gamma -secretase activities. Implications for the role of presenilin in gamma secretase cleavage. I Biol Chem 2000, 275:26277-84.

57. Zhang L, Song L, Terracina G, Liu Y, Pramanik B, Parker E: Biochemical characterization of the gamma-secretase activity that produces beta-amyloid peptides. Biochemistry 200I, 40:5049-55.

58. Sato T, Diehl TS, Narayanan S, Funamoto S, Ihara Y, De Strooper B, Steiner $\mathrm{H}$, Haass $\mathrm{C}$, Wolfe MS: Active gamma-secretase complexes contain only one of each component. J Biol Chem 2007, 282:33985-93.

59. Page RM, Baumann K, Tomioka M, Pérez-Revuelta BI, Fukumori A Jacobsen H, Flohr A, Luebbers T, Ozmen L, Steiner H, Haass C: Generation of Abeta38 and Abeta42 is independently and differentially affected by familial Alzheimer disease-associated presenilin mutations and gamma-secretase modulation. J Biol Chem 2008, 283:677-83.

60. Clarke EE, Churcher I, Ellis S, Wrigley JD, Lewis HD, Harrison T, Shearman MS, Beher D: Intra- or intercomplex binding to the gamma-secretase enzyme. A model to differentiate inhibitor classes. J Biol Chem 2006, 28 I :3 I279-89.

61. Strömberg K, Hansson EM, Laudon H, Bergstedt S, Näslund J, Lundkvist J, Lendahl U: gamma-Secretase complexes containing $\mathbf{N}$ and C-terminal fragments of different presenilin origin retain normal gamma-secretase activity. I Neurochem 2005, 95(3):880-90.

62. Yan R, Han P, Miao H, Greengard P, Xu H: The transmembrane domain of the Alzheimer's beta-secretase (BACEI) determines its late Golgi localization and access to beta -amyloid precursor protein (APP) substrate. J Biol Chem 200I, 276:36788-96.

63. He W, Shi Q, Hu X, Yan R: The membrane topology of RTN3 and its effect on binding of RTN3 to BACEI. J Biol Chem 2007, 282:29|44-5|.

64. Qahwash I, Weiland KL, Lu Y, Sarver RW, Kletzien RF, Yan R: Identification of a mutant amyloid peptide that predominantly forms neurotoxic protofibrillar aggregates. J Biol Chem 2003, 278:23187-95.

\section{Note}

Current address of the authors: Denise D McKinley is current at Musculoskeletal Research, Eli Lilly and Company; 98C/B Drop Code 0403; Indianapolis, IN; Jeffery S. Nye at $\mathrm{CMO}$, East Coast Research and Early Development, Johnson and Johnson Pharmaceutical R\&D, LLC. P.O. Box 776, Welsh \& McKean Roads, Rm 31-2002 Spring House, PA.
Publish with Bio Med Central and every scientist can read your work free of charge

"BioMed Central will be the most significant development for disseminating the results of biomedical research in our lifetime. "

Sir Paul Nurse, Cancer Research UK

Your research papers will be:

- available free of charge to the entire biomedical community

- peer reviewed and published immediately upon acceptance

- cited in PubMed and archived on PubMed Central

- yours - you keep the copyright
BioMedcentral 